\title{
Varicella in COVID-19: A Case Report
}

\author{
Shrestha SK ${ }^{1}$, Joshi $A^{2}$
}

${ }^{1}$ Consultant Dermatologist, Scheer Memorial Adventist Hospital, Banepa, Kavre, Nepal; ${ }^{2}$ Emergency Physician and Lecturer, Patan Academy of Health Sciences, Patan, Nepal

\begin{abstract}
Coronavirus disease-2019 (COVID-19) is the viral pandemic with the propensity of having several systemic manifestations. As with other viral diseases, it has been associated with varied cutaneous manifestations and they range from maculopapular eruptions, vascular lesions to the chickenpox-like lesions. However, the co-occurrence of COVID-19 and varicella has been rarely reported.
\end{abstract}

Key words: Chickenpox; Coronavirus Infections; COVID-19; SARS-CoV-2

\section{Introduction}

$\mathrm{C}$ oronavirus disease-2019 (COVID-19) is the pandemic caused by Severe Acute Respiratory Syndrome Coronavirus 2 (SARS-CoV2) previously referred to as 2019-nCoV. Several viral infections including COVID itself are characterized by the presence of related cutaneous manifestations. Italian study has shown around $20 \%$ of the patients demonstrating cutaneous manifestation in the form of erythematous rash, urticaria and chickenpox-like vesicles mainly in the trunk with little or no itching. ${ }^{1}$ Varicella otherwise commonly known as chicken pox is caused by varicella zoster virus and is a separate entity from COVID19. However, varicelliform eruptions have been well explained in relation to COVID-19 in several literatures but none have found the evidence of existence of varicella zoster virus. Furthermore, none of the skin lesions are correlated with disease severity of COVID. Here we present one atypical case that was diagnosed to have COVID-19 developing varicella concurrently.

\section{Case Report}

A 29 years old male, lawyer by occupation otherwise in well-state of health presented to the COVID clinic of Patan Academy of Health Sciences (PAHS), as a part of contract tracing and submitted nasopharyngeal swab for PCR for SARS-COV2 on the 6th day of primary

Funding: No

Conflict of Interest: No

\section{Address of Correspondence}

Dr. Shree Krishna Shrestha

Consultant Dermatologist

Scheer Memorial Adventist Hospital, Banepa, Nepal

E-mail: shree.shrestha@gmail.com contact. He didn't have any comorbidities nor was under any medications. He started developing lowgrade fever and mild malaise after the day of swab submission. On the 8th day post contact and next day of fever, his swab report was positive for SARS-COV2 (ORF1ab gene CT - 33.96; N gene CT-33.13 and IC Rp gene-25.89). On the same day, he started developing rashes over the face and trunk. He underwent online consultation with us. He didn't remember any recent contact with chickenpox patient nor was there such infection in the family. On examination, there were few discrete erythematous papules and vesicular lesions with red halo over the face, trunk and extremities (Fig.1). Patient denied any such lesions in the past or in family nor does patient remember having chickenpox during childhood. Patient was already on symptomatic management with oral acetaminophen, Vitamin $C$ and Vitamin B with Zinc supplementation Topical fusidic acid was prescribed and online consultation with patient was pursued on regular basis for progression of lesions. On second day, the florid picture of vesicular eruptions was seen. The lesions had increased and each lesion were discrete and vesicular with surrounding erythema and were diffusely distributed over the face, scalp, trunk and extremeties (Fig.2). Enanthems were

Submitted: $19^{\text {th }}$ December 2020

Accepted: $15^{\text {th }}$ January 2021

Published: $20^{\text {th }}$ February 2021

How to cite this article

Shrestha SK, Joshi A. Varicella in COVID-19: A case report. Nepal Journal of Dermatology, Venereology and Leprology 2021;19(1):65-7. https://doi.org/10.3126/njdvl.v19i1.35957.

Licensed under CC BY 4.0 International License which permits use, distribution and reproduction in any medium, provided the original work is properly cited. 
also noticed in the posterior pharyngeal wall (Fig.3). Patient had mild discomfort on swallowing however fever had already subsided and patient didn't have any cough, shortness of breath. The patient was diagnosed as having varicella and prescribed oral acyclovir 800 mg five times a day for 7 days with advice to continue topical fusidic acid and symptomatic management. Lesions continued to appear, being pleomorphic in nature and few started to pustulate on following days (Fig.4). On 5th day post-eruption, lesions started to crust and erythema of lesions was fading. On $10^{\text {th }}$ day post eruption, all lesions faded and seen crusted (Fig.5). Patient was symptomatically better as well. By this time, it was already 14 days post-COVID and patient was therefore advised for repeat PCR. Repeat PCR for SARS-CoV2 was negative. Afterwards, patient was seen in-person. He didn't have any postCOVID symptoms. On examination, he did have post-inflammatory hyperpigmented macules with very few depressed scars over the face (Fig.6). VZV serology was done which showed IgM titre of $>2.30$ (Biological Reference Interval <1.00) and IgG of 1377 $\mathrm{mIU} / \mathrm{ml}$ ) (Biological Reference Interval <150). This further supports the occurrence of the varicella zoster virus infection in the patient at the time of COVID-19 acquisition. The patient was otherwise well afterwards with no complications and was advised to follow up as per need.

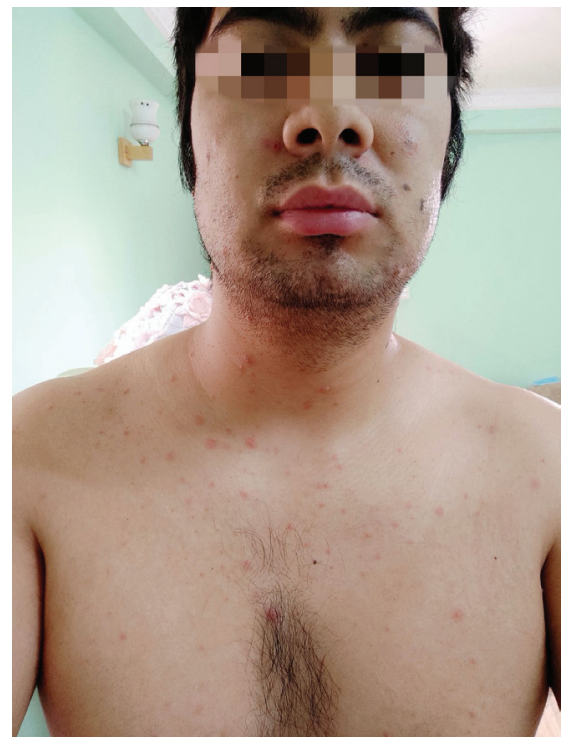

Figure 1: Erythematous papules and vesicles over the face and trunk

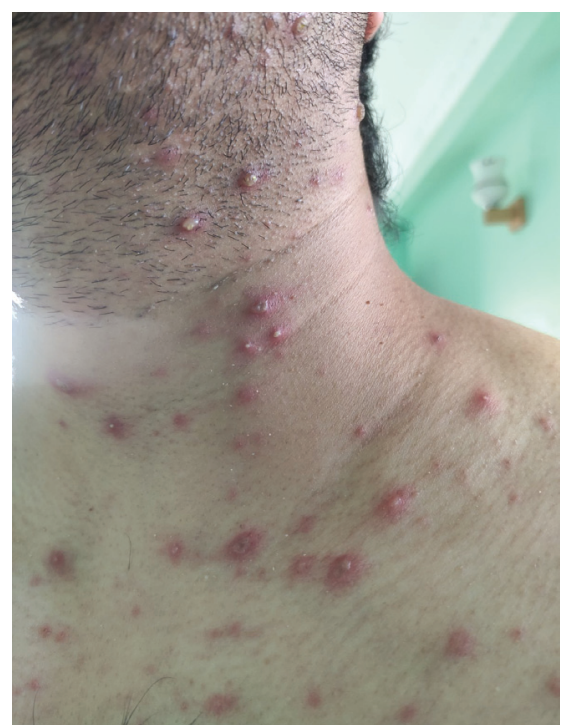

Figure 4: Predominant pustular lesions

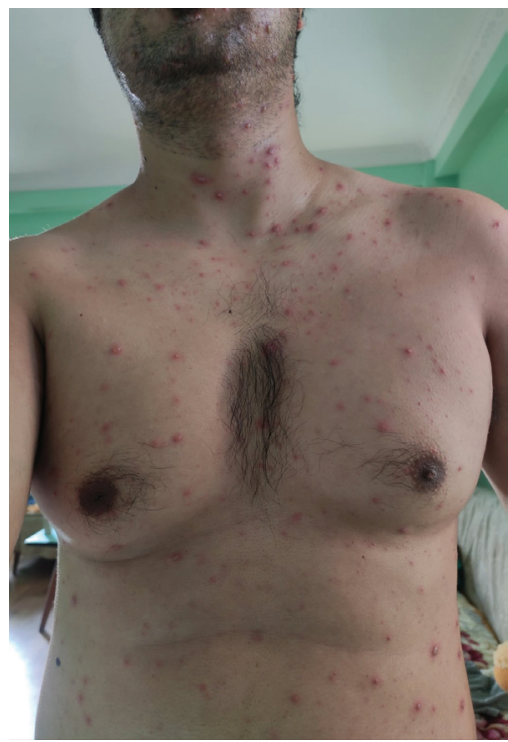

Figure 2: Multiple erythematous papules, vesicles and pustules over the face and trunk

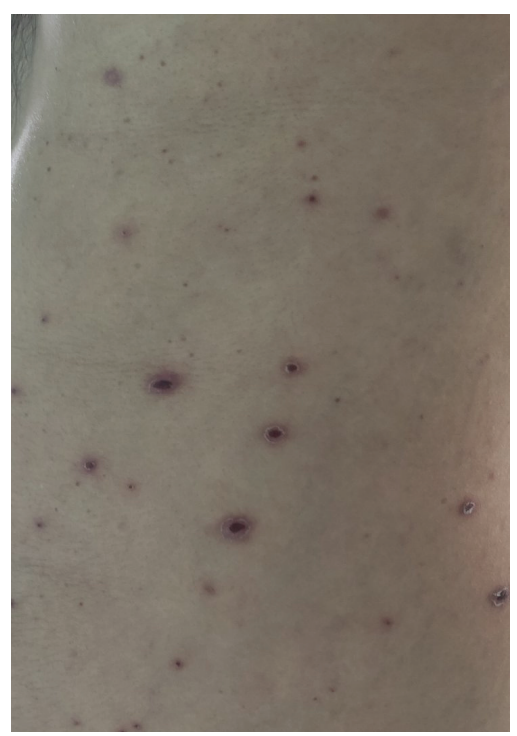

Figure 5: Crusted lesions over the trunk

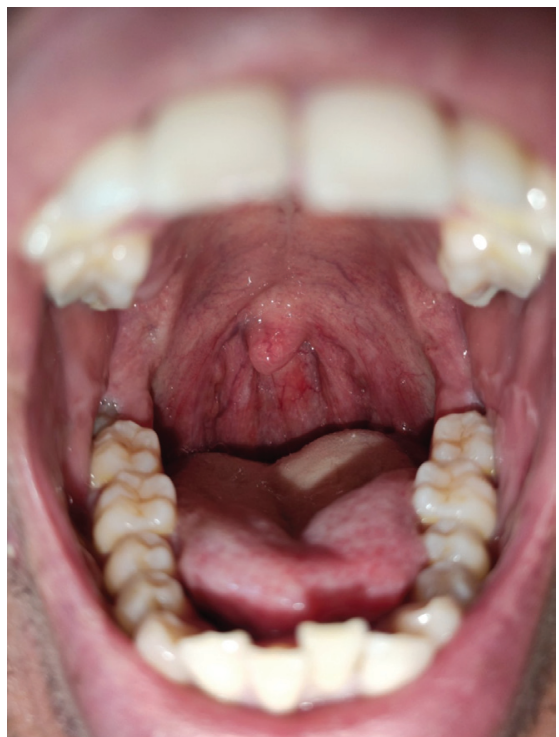

Figure 3: Erythema and ulcer in the posterior pharyngeal wall

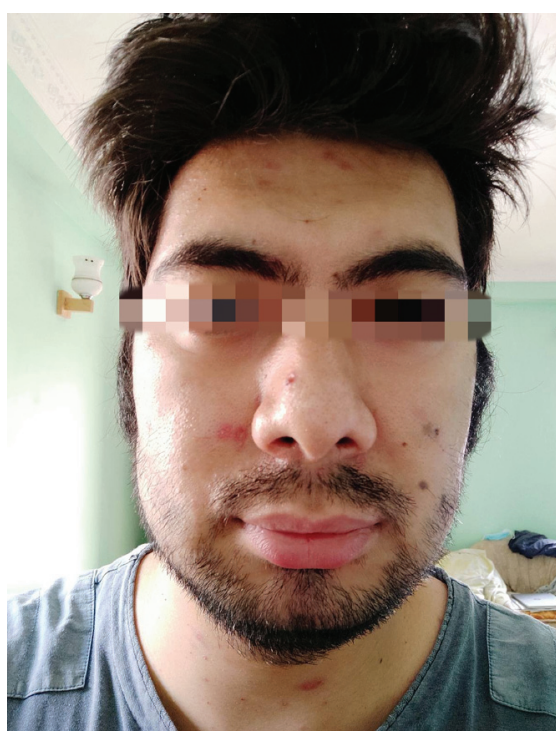

Figure 6: Post inflammatory

hyperpigmentation over the forehead with depressed scar over the nasal bridge 


\section{Discussion}

Co-occurrence of varicella and COVID-19 hasn't been mentioned in literatures. However, varicellalike eruptions are well-illustrated as dermatological manifestations in COVID along with other skin presentations in several literatures. ${ }^{2}$ Earliest data is from China with rash in $0.2 \%$ of patients, without morphologic descriptions. ${ }^{3}$ Later data from Italy collected by dermatologists on the front lines showed rash in $18 / 88$ patients $(20.4 \%)$, excluding patients on new drugs, with erythematous papules in 14, urticaria in 3 and vesicles in 1 patient. ${ }^{4}$ Binational, multicentric prospective study in China and Italy to assess cutaneous involvement during the course of coronavirus disease showed new dermatologic conditions in 53 patients (7.8\%) detected at admission or during hospitalization. ${ }^{5}$ of the dermatologic conditions, $44 \%$ were present on day of the COVID-19 diagnosis and remaining was observed at the mean of 11.7 days. Over $70 \%$ has erythematous rashes of maculopapular variant while only $4 \%$ had scattered vesicular varicelliform eruptions. Herpes simplex virus and varicella zoster virus were ruled out by performing PCR from lesions. Marzano et al. have observed

\section{References}

1. Drenovska K, Schmidt E, Vassileva S. Covid-19 pandemic and the skin. Int J Dermatol 2020;59:1312-9. https://doi.org/10.1111/ijd.15189

2. Marzano AV, Genovese G, Fabbrocini G, Pigatto P, Monfrecola G, Piraccini BM, et al. Varicella-like exanthem as a specific COVID19-associated skin manifestation: Multicenter case series of 22 patients. J Am Acad Dermatol 2020 Jul;83(1):280-5.https://doi.org/10.1016/j. jaad.2020.04.044

3. Guan W, Ni Z, Hu Y, Liang W, Ou C, He J, et al. Clinical Characteristics of Coronavirus Disease 2019 in China. N Eng J Med 2020 Apr;382(18):1708-20. https://doi.org/10.1056/ NEJMoa2002032

4. Recalcati S. Cutaneous manifestations in COVID-19: a first perspective. J Eur varicella-like papulovesicular exanthem as a rare but specific COVID-19-associated skin manifestation. ${ }^{2}$ In varicella, the generalized vesicular eruptions usually follow within 24 hours of the prodromal features and lesions tend to heal with hyper- or hypopigmentation that may persist for weeks and small depressed scars may occur in around $18 \%$ of patients. ${ }^{6}$ While COVID associated varicelliform eruptions generally appear 3 days after systemic symptoms and disappear by 8 days, without leaving scarring.In varicella, immunoglobulins like IgM and IgG appear 2-5 days after the onset of the rash and peak during 2 nd and 3rd weeks, thereafter the titres gradually fall. ${ }^{7}$ The patient presented here is the atypical and rare case association of varicella with COVID-19. The limitation in this case was inability to do Tzanck smear and unavailability of VZV-specific PCR from vesicle fluid.

\section{Conclusion}

Several cutaneous manifestations have been associated with COVID-19 ranging from the commonest maculopapular lesions to the rarer vesicular eruptions. However, the co-infection of varicella with it is the rare occurrence.

Acad Dermatol Venereol 2020;34:e212-3. https://doi.org/10.1111/jdv.16387

5. De Giorgi V, Recalcati S, Jia Z, Chong W, Ding R, Deng $Y$, et al. Cutaneous manifestations related to coronavirus disease 2019 (COVID-19): A prospective study from China and Italy. J Am Acad Dermatol 2020 Aug;83(2):674-5.https://doi. org/10.1016/j.jaad.2020.05.073

6. Sterling JC. Herpesvirus Infections. In: Christopher Griffiths, Jonathan Barker, Tanya Bleiker RC and DC, editors. Rook's Textbook of Dermatology. Ninth Edition. Wiley-Blackwell; 2016. p. 25.2425.26 .

7. Dogger-Goren S, Daba K, Hurley P, Yabuuchi H, Takahashi M, Ogra PL. Antibody Response to Varicella-Zoster Virus after Natural or Vaccine-Induced Infection. J Infect Dis 1982 Aug;146(2):260-5. https://doi.org/10.1093/infdis/146.2.260 